\title{
Review of applications of microneedling in dermatology
}

This article was published in the following Dove Press journal:

Clinical, Cosmetic and Investigational Dermatology

8 August 2017

Number of times this article has been viewed

\author{
Christopher Iriarte' \\ Olabola Awosika² \\ Monica Rengifo-Pardo ${ }^{1,2}$ \\ Alison Ehrlich ${ }^{1,2}$ \\ 'George Washington University \\ School of Medicine and Health \\ Sciences, Washington, DC, USA; \\ 2Department of Dermatology, The \\ George Washington Medical Faculty \\ Associates, Washington, DC, USA
}

Correspondence: Alison Ehrlich Department of Dermatology, The George Washington University Medical Faculty Associates, 2150 Pennsylvania Avenue NW, Suite 2B-430, Washington, DC 20037, USA

Tel + I $20274 \mid 2625$

Email aehrlich@mfa.gwu.edu
Abstract: Microneedling (MN) is a novel therapeutic modality in dermatology. Through physical trauma from needle penetration, $\mathrm{MN}$ induces a wound healing cascade with minimal damage to the epidermis. This allows for enhancement in the absorption of mainstay topical therapies across the thick stratum corneum. MN has become increasingly utilized over the last several years as it is a relatively simple procedure that is cost-effective, well tolerated, and offers both cosmetic and therapeutic benefits. The ability to treat localized areas of disease has led to numerous studies gauging its potential in focal diseases of inflammation, dyschromia, and photodamage. This review discusses the principles and evidence behind the expanding applications of MN. It has shown promising results as an adjuvant therapy for enhanced drug delivery in the treatment of atrophic scars, alopecia, actinic keratoses, and disorders of pigmentation such as melasma. The efficacy in treatment of vitiligo remains limited. Overall, the procedure has few adverse sequelae compared to other therapies, is highly efficacious, and is a viable resurfacing option for skin of color. Future research is needed to determine the frequency, interval, and specific device settings that foster optimal results. Additionally, large controlled trials are needed to shed light on the utility of MN as an evidence-based regimen for the treatment of various dermatologic conditions.

Keywords: microneedling, scars, acne, alopecia, hyperpigmentation, actinic keratosis

\section{Introduction}

Microneedling (MN), also known as collagen induction therapy, is a process involving repetitive puncturing of the skin with sterilized microneedles. Its original conception can be traced back to 1995, when Orentreich and Orentreich developed the concept of "subcision", or using hypodermic needles to induce wound healing in depressed cutaneous scars. ${ }^{1}$ In 2006, Dr. Desmond Fernandes developed the first MN product which became the modern-day Dermaroller ${ }^{\circledR}$ (Dermaroller Deutschland GmbH, Wolfenbuettel, Germany). ${ }^{2}$

$\mathrm{MN}$ offers a relatively low cost and minimally invasive tool for the treatment of multiple cosmetic and dermatologic conditions. ${ }^{3}$ The basis of $\mathrm{MN}$ relies on physical trauma. It has been proposed that the trauma generated by needle penetration in the skin induces regeneration of the dermis. ${ }^{4}$ The needles penetrate the stratum corneum and create small holes known as micro-conduits with minimal damage to the epidermis. This sequentially leads to the generation of growth factors which stimulate the production of collagen and elastin in the papillary layer of the dermis. ${ }^{3}$ The natural wound healing cascade is induced as platelets and neutrophils are recruited to release growth factors such as TGF-alpha, TGF-beta, and platelet-derived growth factor (PDGF). ${ }^{2}$ This ultimately results in the deposition of collagen by fibroblasts. 
A variety of $\mathrm{MN}$ products have been developed to treat scarring and wrinkles, enable skin rejuvenation, and improve skin appearance. ${ }^{5}$ Clinical trials over the last several years have shed light on the applications of $\mathrm{MN}$ beyond cosmetic indications, including actinic keratoses (AK), disorders of pigmentation, hyperhidrosis, and striae. ${ }^{6}$ Additionally, the role of $\mathrm{MN}$ in the treatment of hair pathology has become a recent field of focus as it is thought to stimulate stem cells in the dermal papilla, increase blood flow to hair follicles, and recruit growth factors and signaling pathways which induce hair restoration. ${ }^{7} \mathrm{MN}$ is also postulated to induce normal wound healing, specifically by breaking collagen strands in the superficial dermis and inducing collagen synthesis immediately under the epidermis. ${ }^{8}$ This mechanism is the guiding principle behind the application of $\mathrm{MN}$ in the treatment of scars of various etiologies.

This review of the literature is focused on exploring the expanding indications of MN. In addition, this review will highlight the efficacy and adverse effect prolife of $\mathrm{MN}$ in comparison with more common treatment modalities used for various indications in dermatology.

\section{Methods}

The studies selected for this review were gathered by searching the PubMed, MEDLINE, Cochrane databases, and electronic journals of dermatology. The search terms used for this review included "microneedling", "collagen induction", "reviews", and "trials". Only articles published in English were considered for inclusion in this review. Articles were obtained in all circumstances and references were checked for additional information when considered applicable. Available studies involving human subjects were included in the review. Additionally, only studies regarding manual MN techniques were considered for inclusion. Priority was given to controlled clinical trials, both prospective and retrospective, with a minimum of ten patients as the sample size. Uncontrolled clinical trials were included so long as a statement was made regarding the study's experimental design and limitations. Smaller case series with less than ten patients were included if they were the only available data for specific indications such as alopecia areata (AA) or verruca plantaris.

\section{Types of $\mathbf{M N}$}

Currently, there are many mechanical $\mathrm{MN}$ devices registered with the US Food and Drug Administration (FDA), with the majority being a variation of either the Dermaroller or the Dermapen $^{\circledR}$ (Dermapen, Salt Lake City, UT, USA). The Dermaroller is a hand-held device with a cylindrical roller of 24 circular arrays. ${ }^{6,9}$ Each array is equipped with eight medical grade solid steel microneedles, totaling to 192 needles on one Dermaroller device. ${ }^{6,9}$ The device is used in a multi-directional fashion (vertically, horizontally, and diagonally) directly over the skin. Medical models include the CIT $8^{\mathrm{TM}}$ and MF $8^{\mathrm{TM}}$, which consist of needle heights of $500 \mu \mathrm{m}$ and $1,500 \mu \mathrm{m}$, respectively. ${ }^{6}$ Various models have also been developed for use in the home, including the Beauty Mouse ${ }^{\circledR}$ (Dermaroller Deutschland $\mathrm{GmbH}$ ) which consists of 480 needles to use on larger skin surfaces. ${ }^{5}$ The Dermapen is a spring-loaded $\mathrm{MN}$ device which acts as an electrically powered pen, delivering stamp-like motions across the skin. ${ }^{10}$ Several commercial variations of this device exist based on the same principles.

Other devices use additional technology to build upon the applications of mechanical MN. Indications for these newer modalities include superficial scars, hyperhidrosis, and wrinkles. ${ }^{6}$ These $\mathrm{MN}$ modalities include fractional radiofrequency microneedling (FRFM), DermaFrac ${ }^{\mathrm{TM}}$ (Genesis Biosystems, Lewisville, TX, USA), light emitting diode (LED) $\mathrm{MN}$ devices, and MN delivery systems. ${ }^{6}$ FRFM is differentiated from manual $\mathrm{MN}$ due to the method of each insulated needle releasing a radiofrequency current from the needle tip producing changes in dermal structural components. ${ }^{6,11}$ In DermaFrac treatment, $\mathrm{MN}$ is combined with microdermabrasion, LED light, and simultaneous serum infusion into the dermis. ${ }^{6}$ LED MN rollers combine solely LED light and MN. MN delivery systems are a method of transdermal drug administration in which solid microneedles pierce the skin followed by topical drug application. Alternatively, drugs can be delivered directly into the dermis through hollow needles. ${ }^{12}$ Of note, in 2011, Fluzone ${ }^{\circledR}$ Intradermal influenza virus vaccine (Sanofi Pasteur, Swiftwater, PA, USA) became the first and only microneedle-based product approved by the FDA for this process. ${ }^{13,14}$ It is recommended that the use of $\mathrm{MN}$ to enhance absorption of topical agents be performed with caution as non-sterilized drugs may contain particles that penetrate the skin to varying degrees and contribute to further complications, such as infection due to the permeation of pathogenic microbes. ${ }^{12}$

\section{Applications of MN}

The sections that follow will provide an overview of the clinical trials in dermatology that have been performed with manual MN, as well as several case series. Specific information regarding study design, treatment intervals, $\mathrm{MN}$ devices used, and comparative efficacy can be found in the accompanying tables. These tables summarize the major studies covered in this review for each respective indication 
that follows. Each section concludes with our summary of the current state of the literature and future areas for research specific to each indication.

\section{Scars}

Several studies show efficacy of $\mathrm{MN}$ for scar treatment (Table 1). In a pilot study, El-Domyati et al quantified the histological changes induced by $\mathrm{MN}$ in ten patients with atrophic facial scars from acne. ${ }^{15}$ Skin biopsies were obtained at baseline and post-treatment with Dermaroller. There was a statistically significant increase in the production of collagen types I, III, and VII and a decrease in total elastin by the end of treatment $(p<0.05)$. All patients reported mild pain and edema at the treatment site which resolved within 24 hours. Otherwise, no adverse effects were noted. Patients collectively reported a 51\%-60\% improvement in scar appearance, $40 \%-50 \%$ improvement in skin texture, and $80 \%-85 \%$ overall satisfaction $(p=0.001)$ following six treatment sessions over the course of 3 months. ${ }^{15}$

In a cohort study, Majid relied on clinical outcomes rather than histologic changes to assess improvement of atrophic facial scars in response to $\mathrm{MN}$ therapy. ${ }^{16}$ Thirty-seven patients were offered Dermaroller treatments and followed over the course of 2 months. Over $80 \%$ of the patients assessed their response to treatment as "excellent" on a 10-point scale. Of the patients who completed the study, $94.4 \%$ graded the reduction in the severity of their scars by at least one objective grade. No adverse effects were noted. ${ }^{16}$

A clinical trial by Garg and Baveja assessed the efficacy of combination therapy using subcision, $\mathrm{MN}$, and $15 \%$ trichloroacetic acid peel in the management of 50 patients with atrophic acne vulgaris scars. ${ }^{17}$ The patients were treated for a total of six sessions with scar grading done at baseline and 1 month after treatment. Complete remission was demonstrated in all patients with Grade 2 scars and $22.7 \%$ of patients with Grade 3 scars. Additionally, of the 16 patients with Grade 4 scars at baseline, ten patients improved to Grade 2 and the remaining six improved to Grade 3 . Overall, $100 \%$ of patients had objective improvement in scars by at least 1 grade. Adverse events other than transient erythema and edema included acne eruptions, post-inflammatory hyperpigmentation $(\mathrm{PIH})$ resolving after 5 months of topical treatment (with combination of tretinoin, hydroquinone, and mometasone), and cervical lymphadenopathy lasting 3 weeks. ${ }^{17}$

Several studies have also compared the efficacy of laser and $\mathrm{MN}$ treatments. Cachafeiro et al compared 1,340 nm nonablative fractional erbium laser and Dr. Roller ${ }^{\mathrm{TM}}$ (Vydence Medical, São Carlos, São Paulo, Brazil) for the treatment of
46 patients with facial atrophic acne scars. ${ }^{18}$ These patients were randomized to one of the two groups and received three treatment sessions monthly regardless of assignment. Both groups demonstrated improvement at 2 and 6 months posttreatment, with no statistically significant difference between them $(p=0.264)$. While efficacy was similar, the adverse event profile varied. The $\mathrm{MN}$ group experienced erythema for an average of 1 day compared to the laser group, for which the erythema lasted an average of 3 days. Additionally, $13.6 \%$ of the patients in the laser group experienced $\mathrm{PIH}$ while none of the patients in the $\mathrm{MN}$ group did. ${ }^{18}$

Another emerging field of study in $\mathrm{MN}$ is its applicability in the treatment of scars in various ethnic groups. One clinical trial by Dogra et al evaluated the utility of $\mathrm{MN}$ for treating atrophic acne scars in Asian populations. ${ }^{19}$ On an objective scale of 18 points, patients' assessments of their scars decreased from 11.73 to 6.5 following five $\mathrm{MN}$ treatments, indicating significant improvement. In a study with patients of darker pigmented skin, the use of $\mathrm{MN}$ combined with glycolic acid peels for the treatment of acne scars was assessed in 30 Indian patients with atrophic box type and rolling scars with PIH. ${ }^{20}$ Patients were assigned to receive treatment with MN only or with MN and 35\% glycolic acid peels. There was significant improvement in skin texture, scarring, and a reduction in $\mathrm{PIH}$ in the group treated with the combined approach when compared to $\mathrm{MN}$ alone $(p=0.001) .^{20}$

MN has also been used to enhance treatment of hypertrophic surgical scars by increasing drug delivery of topical agents to the dermis. ${ }^{21}$ Aust et al demonstrated $\mathrm{MN}$ to be an effective alternative for burn patients with hypertrophic scars. $^{22}$ In this study, 16 patients with post-burn scarring were treated with $\mathrm{MN}$ after 4 weeks of preparation with topical vitamin $\mathrm{A}$ and $\mathrm{C}$ to maximize collagen production. Each patient reported satisfaction with scar appearance on an objective visual analog scale (VAS) from 1 to 10 , with 10 indicating the most satisfaction. Prior to treatment, the average VAS score was 4.5. This score increased to 8.5 following one to four sessions of $\mathrm{MN}$ treatment with continued application of topical vitamin $\mathrm{A}$ and $\mathrm{C}$ twice daily. Histologic analysis of $3 \mathrm{~mm}$ punch biopsies at 1 year demonstrated an increase in collagen and elastin deposition both quantitatively and qualitatively using van Gieson and hematoxylin and eosin stains.

Studies with various-sized $\mathrm{MN}$ devices that evaluate the frequency and interval between treatments for optimal effects, would be an appropriate next step in further elaborating on the efficacy of MN. Many of the aforementioned studies demonstrated that $\mathrm{MN}$ had comparable efficacy to laser treatments 


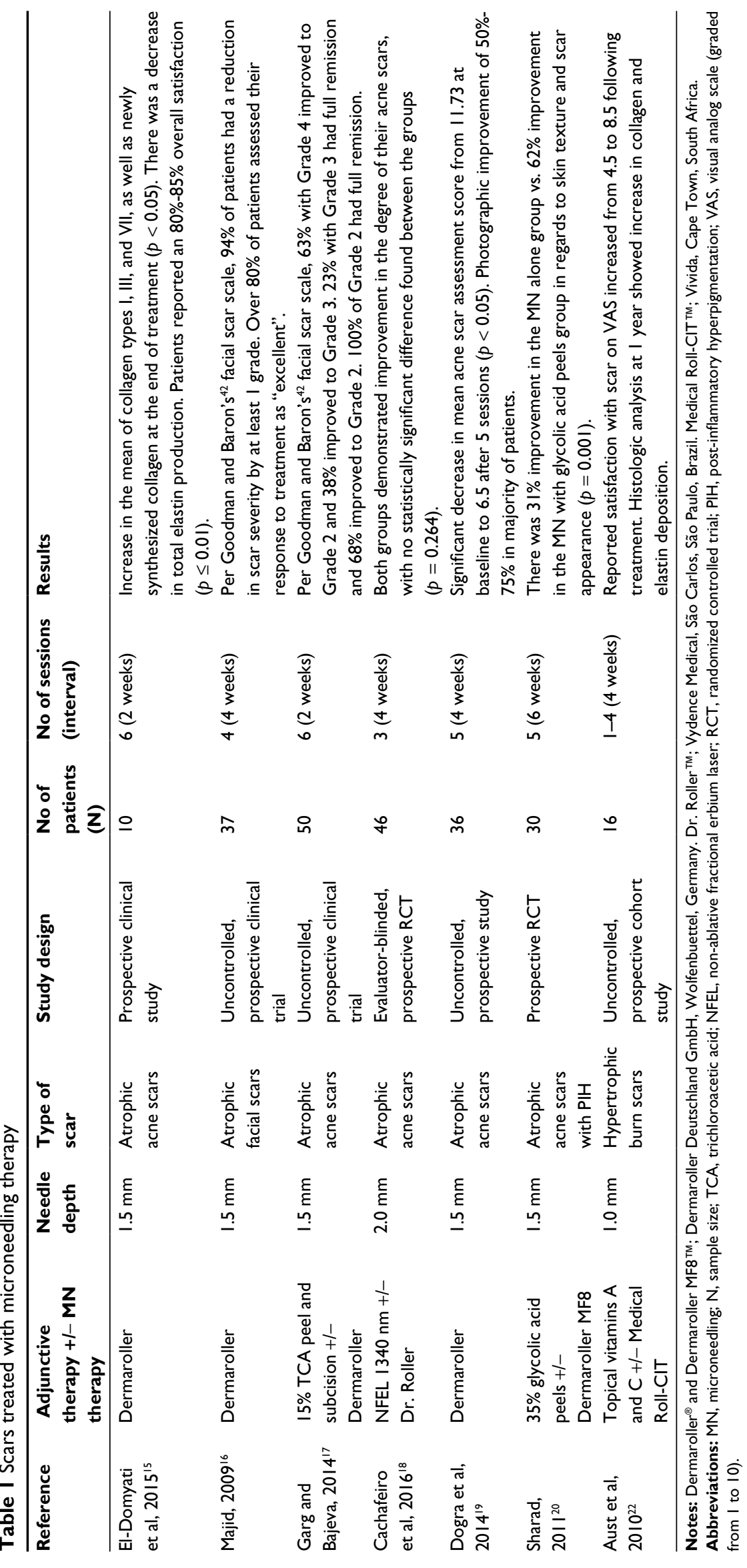


for atrophic facial scars. However, $\mathrm{MN}$ is generally better tolerated with fewer long-term adverse sequelae. ${ }^{23}$ Scar type appears to be a factor affecting clinical response to $\mathrm{MN}$, as icepick scars and deep-seated atrophic scars responded less ideally to treatment. ${ }^{15}$

\section{Alopecia}

$\mathrm{MN}$ has been proposed as a mechanism for adjuvant hair regrowth in alopecia. The efficacy of $\mathrm{MN}$ in both androgenetic alopecia (AGA) and AA has been highlighted over the last 5 years (Table 2 ).

\section{AGA}

Dhurat et al found that combination treatment of $\mathrm{MN}$ with minoxidil was statistically superior to minoxidil alone in the treatment of 100 male patients with AGA. ${ }^{24}$ Over 12 weeks, Dermaroller treatment combined with $5 \%$ minoxidil lotion was administered to half of the participants, with $80 \%$ showing moderately or greatly increased hair regrowth per the investigators. Of the same subset, $82 \%$ of the patients reported subjective improvement greater than $50 \%$ in their hair growth. In the arm receiving 5\% minoxidil alone, only $4.5 \%$ of patients reported greater than $50 \%$ improvement. By the end of the study, mean change in hair count was significantly greater for the MN group (91.4 vs. 22.2, $p=0.039)$.
Additionally, the initiation of new hair growth was first noticeable at 6 weeks in the MN group compared to 10 weeks in the minoxidil alone group. No adverse effects were noted by any of the participants. ${ }^{24}$

Dhurat and Mathapati then published a follow-up case series of four men with AGA unresponsive to conventional treatments. Combination therapy was administered to participants with their prior treatment regimen (either topical minoxidil or oral finasteride) and Dermaroller over a course of 6 months. ${ }^{25}$ All four patients had moderately or greatly increased hair regrowth and reported subjective increases in hair thickness after 1 month of treatment. ${ }^{25}$

\section{AA}

$\mathrm{MN}$ has been proposed as a viable alternative to conventional treatment for AA as well. The mainstay of therapy for AA is currently intralesional corticosteroids, such as kenalog (ILK). However, the collagen induction offered by $\mathrm{MN}$ is thought to counter steroid-induced atrophy as well as cause less pain than injection. ${ }^{26}$

Chandrashekar et al analyzed outcomes from treating resistant AA with $\mathrm{MN}$ and topical corticosteroids. ${ }^{26}$ Two adult patients with AA recalcitrant to ILK, topical steroids, and minoxidil 5\% lotion received topical triamcinolone applied before and after Dermaroller. Both patients graded

Table 2 Alopecia treated with microneedling therapy

\begin{tabular}{|c|c|c|c|c|c|c|c|}
\hline Reference & $\begin{array}{l}\text { Adjunctive } \\
\text { therapy }+I- \\
\text { MN therapy }\end{array}$ & $\begin{array}{l}\text { Needle } \\
\text { depth }\end{array}$ & $\begin{array}{l}\text { Type of } \\
\text { alopecia }\end{array}$ & Study design & $\begin{array}{l}\text { No of } \\
\text { patients } \\
\text { (N) }\end{array}$ & $\begin{array}{l}\text { No of } \\
\text { sessions } \\
\text { (interval) }\end{array}$ & Results \\
\hline $\begin{array}{l}\text { Dhurat et al, } \\
2013^{24}\end{array}$ & $\begin{array}{l}5 \% \text { topical } \\
\text { minoxidil +/- } \\
\text { Dermaroller }\end{array}$ & $1.5 \mathrm{~mm}$ & AGA & $\begin{array}{l}\text { Prospective, } \\
\text { evaluator-blinded } \\
\text { RCT }\end{array}$ & 100 & I2 (I week) & $\begin{array}{l}\text { Mean hair counts were } \\
\text { significantly greater in } \mathrm{MN}+ \\
\text { minoxidil group compared } \\
\text { to minoxidil alone group } \\
(91.4 \text { vs. } 22.2, p=0.039) .82 \% \\
\text { in combination group reported } \\
\text { greater than } 50 \% \text { improvement } \\
\text { vs. } 4.5 \% \text { in minoxidil group. }\end{array}$ \\
\hline $\begin{array}{l}\text { Dhurat and } \\
\text { Mathapati, } \\
2015^{25}\end{array}$ & $\begin{array}{l}5 \% \text { topical } \\
\text { minoxidil and } \\
\text { oral finasteride } \\
+ \text { - Dermaroller }\end{array}$ & $1.5 \mathrm{~mm}$ & AGA & Case series & 4 & $\begin{array}{l}4 \text { (I week) then } \\
\text { I I ( } 2 \text { weeks })\end{array}$ & $\begin{array}{l}100 \% \text { showed }+2 \text { or }+3 \text { responses } \\
\text { on a } 7 \text {-point standardized scale } \\
\text { for hair growth. Findings were } \\
\text { sustained at final follow-up. } 75 \% \\
\text { had subjective improvement in } \\
\text { hair growth }>75 \% \text {. }\end{array}$ \\
\hline $\begin{array}{l}\text { Chandrashekar } \\
\text { et al, } 2014^{26}\end{array}$ & $\begin{array}{l}0.1 \% \text { topical TAC } \\
\text { +/- Dermaroller }\end{array}$ & $1.5 \mathrm{~mm}$ & AA & Case series & 2 & 3 (3 weeks) & $\begin{array}{l}100 \% \text { graded hair regrowth as } \\
\text { "excellent" at 3-week follow-up } \\
\text { with no recurrence of } \mathrm{AA} \text { at } \\
12 \text { weeks. }\end{array}$ \\
\hline
\end{tabular}

Notes: Dermaroller ${ }^{\circledR}$; Dermaroller Deutschland $\mathrm{GmbH}$, Wolfenbuettel, Germany.

Abbreviations: MN, microneedling; N, sample size; AGA, androgenetic alopecia; RCT, randomized controlled trial; TAC, triamcinolone; AA, alopecia areata. 
hair regrowth as "excellent" and had no recurrence at 3-month follow-up. The ability to assess for common adverse effects of steroid treatment such as atrophy, scarring, and increased susceptibility to infection were limited in this study.

While these clinical studies show promising data for the efficacy of $\mathrm{MN}$ in the treatment of alopecia, these results are limited by relatively small sample sizes. Additionally, it is unclear if similar results are reproducible in women with hair disorders. Further investigations of combination therapy with minoxidil and finasteride, including $\mathrm{MN}$ frequency, needle size, and duration of treatment are needed to see if these results are reproducible in both genders and sustained over longer periods of time.

\section{Pigmentary disorders}

Several studies have proposed $\mathrm{MN}$ as an alternative to conventional treatment in disorders of pigmentation affecting darker skin types, including melasma, vitiligo, and periorbital hyperpigmentation (Table 3 ).

\section{Melasma}

The enhanced transdermal drug absorption seen with $\mathrm{MN}$ has achieved better results than skin lightening agents alone in the treatment of melasma. ${ }^{27-29}$ Budamakuntla et al observed enhanced results of $\mathrm{MN}$ followed by topical tranexamic acid in comparison to tranexamic acid microinjections in treating moderate to severe melasma in 60 patients. ${ }^{30}$ After three treatment sessions (at 0,4 , and 8 weeks), the patients were followed for 3 months. There was $35.72 \%$ improvement in the mean Melasma Area and Severity Index (MASI) score in the microinjection group $(p<0.01)$ compared to $44.41 \%$ in the MN group $(p<0.001)$. Notably, only $26 \%$ of patients in the microinjection group achieved $50 \%$ improvement compared to $41 \%$ in the MN group. Neither group experienced major side effects, but some reported mild discomfort, burning sensation, and erythema. ${ }^{30}$

In a pilot study, the use of depigmentation serum containing 4-butylresorcinol and sophora-alpha (prenylated flavonoids from the roots of Sophora flavescens) alone was compared to the combination treatment of depigmentation serum and $\mathrm{MN}(\mathrm{MN}+$ serum) in 20 female patients (Fitzpatrick Skin Type III-IV) with melasma. ${ }^{27}$ In the $\mathrm{MN}+$ serum group, baseline mean MASI score decreased by 9.9 points $(p<0.001)$ compared to a 7.1 point decrease $(p<0.05)$ in the serum only group 2 months post-treatment. Results were confirmed by the significant increase in brightness of patients receiving combination treatment in comparison to the group receiving serum alone $(17.4 \%$ vs. $11.2 \% ; p<0.05) .{ }^{27}$

MN combination therapy also has favorable results in melasma when combined with daily sunscreen use. In a retrospective analysis of 22 cases of recalcitrant melasma (unresponsive to topical bleaches and sunscreen), MN was administered followed by night time application of a depigmentation formula $(0.05 \%$ tretinoin $+4 \%$ hydroquinone + $1 \%$ fluocinonide acetonide) and daily tinted sunscreen (SPF 60) 24 hours after initial skin needling. ${ }^{31}$ The procedure was repeated 30 days after the first treatment. All 22 patients reported satisfaction with results at 2 month follow-up. Photographic analysis at 24-month follow-up in eleven patients demonstrated continued maintenance of skin lightening observed at the 2 -month visit. ${ }^{31}$

\section{Vitiligo}

The efficacy of MN in combination treatment for vitiligo remains unclear. Stanimirovic et al investigated repigmentation of patients with resistant bilateral symmetrical vitiligo by comparing treatment with narrowband ultraviolet $\mathrm{B}$ and topical $0.005 \%$ latanoprost solution with and without Dermaroller. ${ }^{32}$ Seventeen patients in each group had repigmentation (37.8\% of treated lesions) and only $8.8 \%$ of repigmenting lesions had greater than $50 \%$ repigmentation. However, there was no statistically significant difference in repigmentation between groups. ${ }^{32}$

\section{Periorbital melanosis}

MN therapy has been successful in the treatment of periorbital hyperpigmentation. One male patient demonstrated 75\%-90\% improvement with DermaFrac treatment (combination of $\mathrm{MN}$ and active ingredients, including kojic acid or anti-aging serum containing myristoyl pentapeptide 17 [SymPeptide], acetyl octapeptide-3 [SNAP 8], palmitoyl pentapeptide-4 [Matrixyl], acetyl hexapeptide-8 [Argirilene] and tripeptide [Syn-ake]) after 12 sessions. ${ }^{33}$ The patient also reported 7 out of 10 improvement on the Patient's Global Assessment scale in his pigmentation.

Kontochristopoulos et al also explored the use of $\mathrm{MN}$ in periorbital hyperpigmentation by treating 13 female patients with $\mathrm{MN}$ followed by $10 \%$ trichloroacetic acid peels. ${ }^{34}$ Almost all patients $(92.3 \%)$ demonstrated significant improvement ("fair or better") according to patient global assessments. Transient side effects including mild discomfort, edema, and erythema were commonly observed. ${ }^{34}$ 


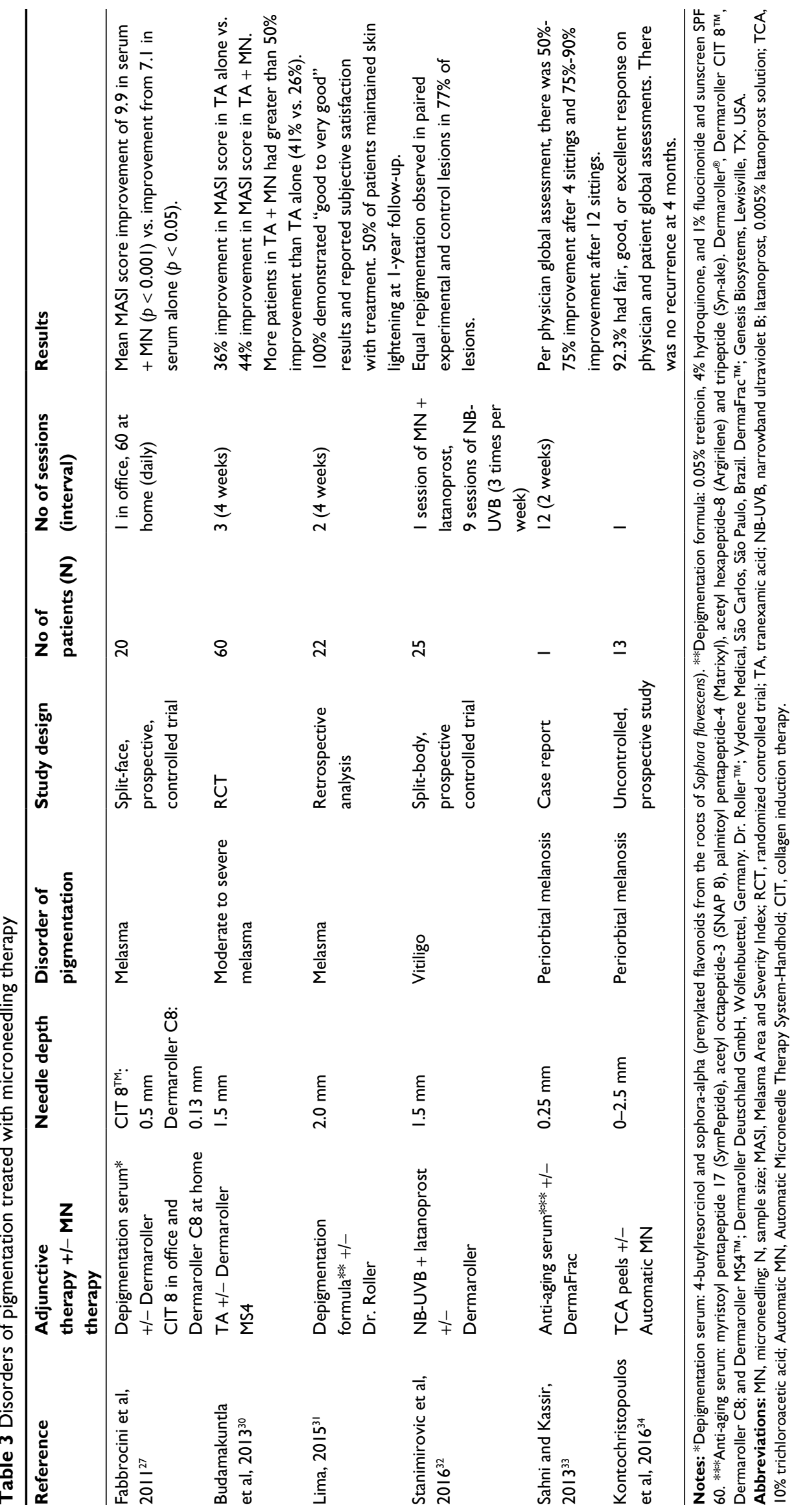


Table 4 Verruca plantaris treated with microneedling therapy

\begin{tabular}{lllllll}
\hline Reference & $\begin{array}{l}\text { Adjunctive } \\
\text { therapy +/- MN } \\
\text { therapy }\end{array}$ & Needle depth & Study design & $\begin{array}{l}\text { No of patients } \\
\text { (N) }\end{array}$ & $\begin{array}{l}\text { No of sessions } \\
\text { (interval) }\end{array}$ & Results \\
\hline $\begin{array}{l}\text { Konicke and } \\
\text { Olasz, 2016 }\end{array}$ & $\begin{array}{l}\text { Bleo }+/- \\
\text { MN pen }\end{array}$ & $2.0 \mathrm{~mm}$ & Case series & 3 & $3-5$ & $\begin{array}{l}\text { Complete cure rate was achieved in } \\
100 \% \text { of patients after an average of } \\
4 \text { treatments every 2-4 weeks. }\end{array}$ \\
\hline
\end{tabular}

Abbreviations: $\mathrm{MN}$, microneedling; $\mathrm{N}$, sample size; Bleo, $0.2-0.5 \mathrm{~mL}$ of topical bleomycin; $\mathrm{MN}$ pen, microneedling pen-type device.

MN therapy is promising in melasma and periorbital melanosis. Notably, MN poses a viable alternative to resurfacing procedures for darker skinned patients, given the lack of dyspigmentation as an adverse event. However, there are limited data to support its potential in improving vitiligo. Hence, there is a need for randomized controlled studies with larger populations to further explore the potential of $\mathrm{MN}$ as a treatment for pigmentation disorders in skin of color.

\section{Verruca}

The benefits of MN as a method of drug delivery in verruca was seen by Konicke and Olasz achieving complete cure rate in three patients (Table 4). MN was used in combination with $0.2-0.5 \mathrm{~mL}$ of topical bleomycin at 1 unit per $\mathrm{mL}$ over an average of 4 treatments. ${ }^{35}$ Notably, there was no tissue necrosis as seen with intralesional bleomycin and patients reported minimal pain. Comparatively, cure rates with intralesional bleomycin range from $0 \%$ to $95 \%$, with variability attributed to poor infiltration of the lesion. ${ }^{36} \mathrm{MN}$ may be a viable option for guaranteeing complete cure rates in plantar warts through enhancing the delivery of bleomycin in lesions.

Clinical trials with large sample sizes are needed to elucidate the actual role of $\mathrm{MN}$ in the treatment of verruca. The above study focused on the treatment of isolated verruca plantaris; thus, large clinical trials analyzing the efficacy of MN in the treatment of common warts would be an area of further research.

\section{Actinic keratoses}

Patients with $\mathrm{AK}$ have shown mixed results from $\mathrm{MN}$ as adjunctive therapy to currently accepted treatments (Table 5). In a split-face study, Torezan et al evaluated the use of MN after application of methyl aminolevulinate photodynamic therapy (MAL-PDT) compared to the use of MAL-PDT without $\mathrm{MN}$ in ten patients with AK. ${ }^{37} \mathrm{MAL}-\mathrm{PDT}$ combined with Dermaroller (MN-MAL-PDT) had greater improvement than MAL-PDT alone for all measured parameters, including photoaging and facial erythema ( $p=0.01$ for global score).

Table 5 Actinic keratoses treated with microneedling therapy

\begin{tabular}{|c|c|c|c|c|c|c|}
\hline Reference & $\begin{array}{l}\text { Adjunctive } \\
\text { therapy }+I- \\
\text { MN therapy }\end{array}$ & $\begin{array}{l}\text { Needle } \\
\text { depth }\end{array}$ & Study design & $\begin{array}{l}\text { No of } \\
\text { patients (N) }\end{array}$ & $\begin{array}{l}\text { No of sessions } \\
\text { (interval) }\end{array}$ & Results \\
\hline $\begin{array}{l}\text { Torezan et al, } \\
2013^{37}\end{array}$ & $\begin{array}{l}\text { MAL-PDT +/- } \\
\text { Dermaroller }\end{array}$ & $1.5 \mathrm{~mm}$ & $\begin{array}{l}\text { Split-face, } \\
\text { prospective RCT }\end{array}$ & 10 & $\mathrm{I}$ & $\begin{array}{l}\text { Average AK clearance was } 88.3 \% \text { overall, } \\
\text { but there was no statistically significant } \\
\text { difference in clearance rates between groups. } \\
\text { MN group had improvement in wrinkles } \\
\text { and erythema. MN group had greater } \\
\text { improvement for all measured parameters, } \\
\text { including global score }(p=0.0 \mathrm{I}) \text {. }\end{array}$ \\
\hline $\begin{array}{l}\text { Spencer and } \\
\text { Freeman, } \\
2016^{38}\end{array}$ & $\begin{array}{l}\text { ALA-PDT +/- } \\
\text { Eclipse } \\
\text { Micropen Elite }\end{array}$ & $0.5 \mathrm{~mm}$ & $\begin{array}{l}\text { Split-face, } \\
\text { blinded, } \\
\text { prospective RCT }\end{array}$ & 19 & I & $\begin{array}{l}\text { Mean reduction in } \mathrm{AK} \text { was } 89.3 \% \text { in the } \mathrm{MN} \\
\text { group vs. } 69.5 \% \text { in the PDT alone group } \\
(p<0.05) .87 \% \text { in } \mathrm{MN} \text { group had noticeable } \\
\text { cosmetic improvement compared to II\% in } \\
\text { PDT alone group. }\end{array}$ \\
\hline $\begin{array}{l}\text { Bencini et al, } \\
2012^{39}\end{array}$ & $\begin{array}{l}\text { MAL-PDT +/- } \\
\text { Dermaroller } \\
\text { MC905 }\end{array}$ & $0.5 \mathrm{~mm}$ & $\begin{array}{l}\text { Uncontrolled, } \\
\text { prospective } \\
\text { clinical trial }\end{array}$ & 12 & 3 (2 weeks) & $\begin{array}{l}\text { I00\% demonstrated a complete response } \\
\text { (grade 0, “excellent") after } 3 \text { treatment } \\
\text { sessions. } 83 \% \text { remained without AK at } \\
\text { 9-month follow-up. }\end{array}$ \\
\hline
\end{tabular}

Notes: Dermaroller ${ }^{\oplus}$; Dermaroller Deutschland GmbH, Wolfenbuettel, Germany. Eclipse Micropen Elite ${ }^{\mathrm{TM}}$; Eclipse Aesthetics, Dallas, TX, USA. Dermaroller MC905 ${ }^{\mathrm{TM}}$; Alpha Strumenti, Milan, Italy.

Abbreviations: MN, microneedling; N, sample size; MAL-PDT, methyl aminolevulinate photodynamic therapy; RCT, randomized controlled trial; AK, actinic keratoses; ALA-PDT, delta aminolevulinic acid photodynamic therapy. 
Average AK clearance was $88.3 \%$, with no statistically significant difference between the treatment arms $(90.5 \%$ for MN-MAL-PDT side vs. $86 \%$ for MAL-PDT side). Pain level, based on VAS score, was greater on the MN-MAL-PDT side (6 vs. $4, p=0.004$ ). No prolonged side effects were observed. One patient in the MN group did develop a secondary bacterial infection which required treatment with oral antibiotics. ${ }^{37}$

Spencer and Freeman demonstrated MN can enhance topical delta aminolevulinic acid PDT (ALA-PDT) in the treatment of $\mathrm{AK} .{ }^{38}$ In their split-face study, 20 patients with at least four non-hyperkeratotic $\mathrm{AK}$ on each side of the face were randomly assigned to either MN therapy with Eclipse Micropen Elite ${ }^{\mathrm{TM}}$ followed by ALA-PDT or ALA-PDT alone. Researchers found a statistically significant difference $(p<0.05)$ between treatment groups, as average AK clearance was $89.3 \%$ in the $\mathrm{MN}$-assisted side and $69.5 \%$ in the PDT only side. Furthermore, a blinded assessment found 15 patients achieved significant cosmetic improvement after 4 months, with 13 of the 15 patients having been in the $\mathrm{MN}$ treatment group. The procedure was safe and well tolerated with no significant side effects reported. ${ }^{38}$

The use of $\mathrm{MN}$ to treat $\mathrm{AK}$ was also evaluated in 12 organ transplant recipients with $59 \mathrm{AK}$ unresponsive to classic PDT therapy. ${ }^{39}$ They received three sessions of cyclic PDT with use of Dermaroller MC905 ${ }^{\mathrm{TM}}$ prior to topical application of 16\% MAL. All lesions demonstrated a grade 0 (excellent) response after three sessions and were free of any new $\mathrm{AK}$ for at least 4 months. At 9 month follow-up, two of the patients had relapsed while the others remained clear. No adverse events were reported. The lack of a PDT alone comparison arm impaired the ability to assess the advantage offered solely by $\mathrm{MN}$ in the treatment of recurrent AK. ${ }^{39}$

Overall, MN shows promising results as an adjuvant therapy for the treatment of refractory AK. Large controlled clinical trials are needed to determine the utility of using $\mathrm{MN}$ for AK, especially on areas of the body other than the face.

\section{Conclusion}

Since the development of the first Dermaroller 20 years ago, a variety of new MN devices have been introduced. Accordingly, the applications of $\mathrm{MN}$ in dermatology have expanded to numerous indications over the past several years. This review highlights evidence of the potential for $\mathrm{MN}$ in the treatment of several dermatologic conditions, including disorders of pigmentation, premalignant lesions such as AK, scarring secondary to acne and surgical procedures, and hair pathologies. Advantages include, but are not limited to, the good tolerability of treatment among patients, increased transdermal delivery of drugs, and practicality of use in skin of color. Transient erythema is the most common adverse event. ${ }^{3}$ Granulomatous reaction in response to unauthorized use of topical products not approved for intradermal injection has been reported in three patients receiving $\mathrm{MN}$ therapy at medical spas. ${ }^{40}$ Otherwise, adverse events are rare and never result in systemic toxicity. ${ }^{3}$ Additionally, histologic analysis of skin following $\mathrm{MN}$ treatment has demonstrated an intact epidermis with no changes in melanocyte number, thereby having minimal risks of dyspigmentation relative to currently accepted treatments. ${ }^{41}$ Overall, MN offers a simple yet costeffective therapeutic modality with minimal adverse events and a promising safety profile.

It is important to keep in mind that most comparative studies on $\mathrm{MN}$ have been case reports, case series, or small randomized controlled trials. Future large controlled clinical trials exploring the utility of $\mathrm{MN}$ are imperative to provide validation as more than a cosmeceutical therapy and as an evidence-based treatment option for patients with a variety of dermatologic disorders. This would help offset any potential publication bias as it is likely that small negative MN studies may not get published. Furthermore, the necessary number of treatment sessions and ideal MN settings including needling length and depth should be explored. Lastly, research elucidating the details of the mechanism of action of MN specifically in the treatment of alopecia and pigmentary disorders would be beneficial, as the micro-conduits created by $\mathrm{MN}$ are fast-healing and increased delivery in the dermis may not be the sole contributor to observed effects in these areas.

\section{Disclosure}

Doctor Olabola Awosika's fellowship is funded by Janssen Biotech, Inc. The authors report no conflicts of interest in this work.

\section{References}

1. Orentreich DS, Orentreich N. Subcutaneous incisionless (subcision) surgery for the correction of depressed scars and wrinkles. Dermatol Surg. 1995;21(6):543-549.

2. Fernandes D. Minimally invasive percutaneous collagen induction. Oral Maxillofac Surg Clin North Am. 2005;17(1):51-63.

3. Doddaballapur S. Microneedling with dermaroller. J Cutan Aesthet Surg. 2009;2(2):110-111.

4. Lee JC, Daniels MA, Roth MZ. Mesotherapy, microneedling, and chemical peels. Clin Plast Surg. 2016;43(3):583-595.

5. McCrudden MT, McAlister E, Courtenay AJ, González-Vázquez P, Raj Singh TR, Donnelly RF. Microneedle applications in improving skin appearance. Exp Dermatol. 2015;24(8):561-566.

6. Singh A, Yadav S. Microneedling: advances and widening horizons. Indian Dermatol Online J. 2016;7(4):244-254.

7. Jeong K, Lee YJ, Kim JE, Park YM, Kim BJ, Kang H. Repeated microneedle stimulation induce the enhanced expression of hair-growthrelated genes. Int J Trichol. 2012;4(2):117-130. 
8. Fabbrocini G, Fardella N, Monfrecola A, Proietti I, Innocenzi D. Acne scarring treatment using skin needling. Clin Exp Dermatol. 2009;34(8):874-879.

9. Bahuguna A. Microneedling-Facts and Fictions. Asian J Med Sci. 2013;4:1-4.

10. Arora S, Gupta BP. Automated microneedling device-A new tool in dermatologist's kit-A review. J Pak Med Assoc. 2012;22:354-357.

11. Chandrashekar BS, Sriram R, Mysore R, Bhaskar S, Shetty A. Evaluation of microneedling fractional radiofrequency device for treatment of acne scars. J Cutan Aesthet Surg. 2014;7(2):93-97.

12. Bariya SH, Gohel MC, Mehta TA, Sharma OP. Microneedles: an emerging transdermal drug delivery system. $J$ Pharm Pharmacol. 2012;64(1):11-29.

13. US Food and Drug Administration. FDA Approval Letter - Fluzone Intradermal; 2009. Available from: http://www.fda.gov/BiologicsBloodVaccines/Vaccines/ApprovedProducts/ucm255160.htm. Accessed May $1,2017$.

14. Milewski M, Mitra A. Recent developments in microneedle technology for transdermal drug delivery and vaccination. Drug Development Delivery; 2012. Available from: http://www.specialtypharma.com/Main/ Back-Issues/Recent-Developments-in-Microneedle-Technology-for-48. aspx. Accessed June 23, 2017.

15. El-Domyati M, Barakat M, Awad S, Medhat W, El-Fakahany H, Farag H. Microneedling therapy for atrophic acne scars: an objective evaluation. J Clin Aesthet Dermatol. 2015;8(7):36-42.

16. Majid I. Microneedling therapy in atrophic facial scars: an objective assessment. J Cutan Aesthet Surg. 2009;2(1):26-30.

17. Garg S, Baveja S. Combination therapy in the management of atrophic acne scars. J Cutan Aesthet Surg. 2014;7(1):18-23.

18. Cachafeiro T, Escobar G, Maldonado G, Cestari T, Corleta O. Comparison of nonablative fractional erbium laser $1,340 \mathrm{~nm}$ and microneedling for the treatment of atrophic acne scars: a randomized clinical trial. Dermatol Surg. 2016;42(2):232-241.

19. Dogra S, Yadav S, Sarangal R. Microneedling for acne scars in Asian skin type: an effective low cost treatment modality. J Cosmet Dermatol. 2014;13(3):180-187.

20. Sharad J. Combination of microneedling and glycolic acid peels for the treatment of acne scars in dark skin. J Cosmet Dermatol. 2011;10(4): 317-323.

21. Eilers RE Jr, Ross EV, Cohen JL, Ortiz AE. A combination approach to surgical scars. Dermatol Surg. 2016;42(Suppl 2):S150-156.

22. Aust MC, Knobloch K, Reimers K, et al. Percutaneous collagen induction therapy: an alternative treatment for burn scars. Burns. 2010;36(6): 836-843.

23. Hartmann D, Ruzicka T, Gauglitz GG. Complications associated with cutaneous aesthetic procedures. J Dtsch Dermatol Ges. 2015;13(8):778-786.

24. Dhurat R, Sukesh M, Avhad G, Dandale A, Pal A, Pund P. A randomized evaluator blinded study of effect of microneedling in androgenetic alopecia: a pilot study. Int J Trichology. 2013;5(1):6-11.

25. Dhurat R, Mathapati S. Response to microneedling treatment in men with androgenetic alopecia who failed to respond to conventional therapy. Indian J Dermatol. 2015;60(3):260-263.

26. Chandrashekar B, Yepuri V, Mysore V, Charmalaya V. Alopecia areata-successful outcome with microneedling and triamcinolone acetonide. J Cutan Aesthet Surg. 2014;7(1):63-64.
27. Fabbrocini G, De Vita V, Fardella N, et al. Skin needling to enhance depigmenting serum penetration in the treatment of melasma. Plast Surg Int. 2011;2011:158241.

28. Fabbrocini G, De Vita V, Izzo R, Monfrecola G. The use of skin needling for the delivery of a eutectic mixture of local anesthetics. G Ital Dermatol Venereol. 2014;149(5):581-585.

29. Escobar-Chavez JJ, Bonilla-Martinez D, Villegas-Gonzalez MA, Molina-Trinidad E, Casas-Alancaster N, Revilla-Vazuez AL. Microneedles: a valuable physical enhancer to increase transdermal drug delivery. J Clin Pharmacol. 2011;51(7):964-977.

30. Budamakuntla L, Loganathan E, Suresh DH, et al. A randomised, open-label, comparative study of tranexamic acid microinjections and tranexamic acid with microneedling in patients with melasma. J Cutan Aesthet Surg. 2013;6(3):139-143.

31. Lima Ede A. Microneedling in facial recalcitrant melasma: report of a series of 22 cases. An Bras Dermatol. 2015;90(6):919-921.

32. Stanimirovic A, Kovacevic M, Korobko I, Situm M, Lotti T. Combined therapy for resistant vitiligo lesions: NB-UVB, microneedling, and topical latanoprost, showed no enhanced efficacy compared to topical latanoprost and NB-UVB. Dermatol Ther. 2016;29(5):312-316.

33. Sahni K, Kassir M. Dermafrac ${ }^{\mathrm{TM}}$ : an innovative new treatment for periorbital melanosis in a dark-skinned male patient. $J$ Cutan Aesthet Surg. 2013;6(3):158-160.

34. Kontochristopoulos G, Kouris A, Platsidaki E, Markantoni V, Gerodimou $\mathrm{M}$, Antoniou C. Combination of microneedling and $10 \%$ trichloroacetic acid peels in the management of infraorbital dark circles. $J$ Cosmet Laser Ther. 2016;18(5):289-292.

35. Konicke K, Olasz E. Successful treatment of recalcitrant plantar warts with bleomycin and microneedling. Dermatol Surg. 2016;42(8):1007-1008.

36. Saitta P, Krishnamurthy K, Brown LH. Bleomycin in dermatology: a review of intralesional applications. Dermatologic Surgery. 2008;34(10):1299-1313.

37. Torezan L, Chaves Y, Niwa A, Sanches JA, Festa-Neto C, Szeimies RM. A pilot split-face study comparing conventional methyl aminolevulinatephotodynamic therapy (PDT) with microneedling-assisted PDT on actinically damaged skin. Dermatol Surg. 2013;39(8):1197-1201.

38. Spencer JM, Freeman SA. Microneedling prior to Levulan PDT for the treatment of actinic keratoses: a split-face, blinded trial. $J$ Drugs Dermatol. 2016;15(9):1072-1074.

39. Bencini PL, Galimberti MG, Pellacani G, Longo C. Application of photodynamic therapy combined with pre-illumination microneedling in the treatment of actinic keratosis in organ transplant recipients. $\mathrm{Br} J$ Dermatol. 2012;167(5):1193-1194.

40. Soltani-Arabshahi R, Wong JW, Duff KL, Powell DL. Facial allergic granulomatous reaction and systemic hypersensitivity associated with microneedle therapy for skin rejuvenation. JAMA Dermatol. 2014:150(1):68-72.

41. Aust MC, Reimers K, Repenning C, et al. Percutaneous collagen induction: minimally invasive skin rejuvenation without risk of hyperpigmentationfact or fiction? Plast Reconstr Surg. 2008;122(5):1553-1563.

42. Goodman GJ, Baron JA. Postacne scarring: a qualitative global scarring grading system. Dermatol Surg. 2006;32(12):1458-1466.
Clinical, Cosmetic and Investigational Dermatology

\section{Publish your work in this journal}

Clinical, Cosmetic and Investigational Dermatology is an international, peer-reviewed, open access, online journal that focuses on the latest clinical and experimental research in all aspects of skin disease and cosmetic interventions. This journal is included on PubMed. The manuscript management system is completely online

\section{Dovepress}

and includes a very quick and fair peer-review system, which is all easy to use. Visit http://www.dovepress.com/testimonials.php to read real quotes from published authors 